\title{
Eaf2 protects human lens epithelial cells against oxidative stress-induced apoptosis by Wnt signaling
}

\author{
$\mathrm{KE} \mathrm{FENG}^{1-3}$ and HAI-KE GUO ${ }^{1,2}$ \\ ${ }^{1}$ Department of Ophthalmology, Southern Medical University; ${ }^{2}$ Department of Ophthalmology, \\ Guangdong General Hospital and Guangdong Academy of Medical Sciences, Guangzhou, Guangdong 510515; \\ ${ }^{3}$ Department of Ophthalmology, Zhengzhou Aier Eye Hospital, Zhengzhou, Henan 450005, P.R. China
}

Received July 5, 2016; Accepted April 24, 2017

DOI: $10.3892 / \mathrm{mmr} .2017 .8246$

\begin{abstract}
The tumor suppressor protein ELL-associated factor 2 (Eaf2) serves an important role in lens development and maturation; however, its role in oxidative stress-induced cataract formation remains unclear. In the present study, an in vitro apoptosis model was constructed by treating HLE-B3 cells with $50 \mu$ M hydrogen peroxide $\left(\mathrm{H}_{2} \mathrm{O}_{2}\right)$, and was confirmed by flow cytometry. Subsequently, overexpression of Eaf2 was induced in $\mathrm{H}_{2} \mathrm{O}_{2}$-induced HLE-B3 cells by ligating Eaf2 cDNA to a pcDNA3.0 plasmid and the role of Wnt3a in the function of Eaf2 was also assessed by inhibiting the expression of the gene in Eaf2-overexpression cells. The expression levels of glycogen synthase kinase $3 \beta, \beta$-catenin, Eaf2, caspase 3 , Wnt3a, B-cell lymphoma 2 (Bcl-2) and Bcl-2-associated X protein were examined using reverse transcription-quantitative polymerase chain reaction and western blot analysis. Immunocytochemistry was used to locate Eaf2 and Wnt3 protein expression in the $\mathrm{H}_{2} \mathrm{O}_{2}$-induced HLE-B3 cells. The results indicated that Eaf2 was able to effectively suppress $\mathrm{H}_{2} \mathrm{O}_{2}$-induced apoptosis of HLE cells via inhibition of caspase 3 production and activation of Wnt 3 a signaling. In addition, knockdown of Wnt3a in Eaf2-overexpression cells evidently counteracted the effect of Eaf2 in antagonizing $\mathrm{H}_{2} \mathrm{O}_{2}$-induced apoptosis. Taken together, these findings suggested that Eaf2 may suppress oxidative stress-induced apoptosis of HLE-B3 cells exerted through the activation of Wnt3a signaling.
\end{abstract}

\section{Introduction}

The reduction in lens transparency caused by cataracts induces severe visual impairment (1), which can seriously effect

Correspondence to: Dr Hai-Ke Guo, Department of Ophthalmology, Guangdong General Hospital and Guangdong Academy of Medical Sciences, 106 Zhongshan Second Road, Guangzhou, Guangdong 510515, P.R. China

E-mail: guohaike2015ghk@163.com

Key words: apoptosis, ELL-associated factor 2, $\mathrm{H}_{2} \mathrm{O}_{2}$, lens epithelial cell, Wnt3a patients' quality of life. Currently, cataract-induced blindness accounts for $\sim 50 \%$ of blindness cases worldwide (2). It is well-recognized that damage resulting from oxidative stress in the ocular lens is a major cause of cataracts (3). The lens is a transparent organ that consists of a single layer of epithelial cells, which are the main target of oxidative stress (4). Oxidative stress caused by exposure to hydrogen peroxide $\left(\mathrm{H}_{2} \mathrm{O}_{2}\right)$ results in DNA damage, and impairs the function of cells and tissues (5). $\mathrm{H}_{2} \mathrm{O}_{2}$, which is a non-free radical member of the active oxygen family, generates hydroxyl radicals that irreversibly damage the lens epithelium, resulting in cell death and cataract formation (6). Some patients with cataracts have markedly increased levels of $\mathrm{H}_{2} \mathrm{O}_{2}$ within their lenses (7), indicating the possible involvement of $\mathrm{H}_{2} \mathrm{O}_{2}$ in the genesis of nuclear cataracts in humans. Therefore, a better understanding of the mechanisms underlying $\mathrm{H}_{2} \mathrm{O}_{2}$-induced apoptosis of lens cells may provide information regarding the cause of cataract formation.

ELL-associated factor 2 (Eaf2) is a protein that was discovered based on its ability to bind with a second protein (eleven-nineteen lysine-rich leukemia protein; ELL), which is independently coded by a gene that is upregulated by androgen in the rat prostate gland and is also named human U19 (8). As a regulator of transcription, Eaf2 interacts with ELL to efficiently stimulate the extension activity of RNA polymerase II (9). It has previously been suggested that Eaf2 serves as a tumor suppressor in prostate cancer (10). Furthermore, knockdown of Eaf 2 has been reported to promote tumorigenesis in mouse models of adenocarcinoma and hepatocellular carcinoma (11). In addition to its role in cancer, Eaf2 serves important roles in embryonic development via its involvement in non-canonical Wnt signaling $(12,13)$, which is thought to be essential for convergence and extension movements, as well as the midline convergence of organ precursors $(14,15)$. Liu et al $(16)$ demonstrated that Eaf2 acts as an upstream modulator of non-canonical Wnt signaling to mediate convergence and extension movements. In addition, the Wnt family of secreted signaling proteins has important roles in organogenesis, tissue homeostasis and tumor formation (17). Overexpression of Wnt3a has been reported to promote the proliferation of human lens epithelial (HLE) cells (18). Furthermore, Eaf2 is required for normal eye development and the regulation of crystalline lens development and maturation in Xenopus laevis $(12,13)$. 
Recently, a related study identified an important role for Eaf2 in ultraviolet-induced cataract formation (19). However, the mechanism underlying the effects of Eaf 2 on lenses undergoing oxidative stress remains unknown.

The present study aimed to investigate the role of Eaf2 in HLE cells undergoing $\mathrm{H}_{2} \mathrm{O}_{2}$-induced apoptosis, and to determine the underlying molecular mechanism. The results indicated that in HLE cells, Eaf 2 protects against $\mathrm{H}_{2} \mathrm{O}_{2}$-induced cell death by inhibiting caspase 3 enzymatic activity and activating the Wnt3 signaling pathway.

\section{Materials and methods}

Cell culture. HLE-B3 cells were purchased from the Cell Bank of the Chinese Academy of Science (Shanghai, China). HLE-B3 cells were cultured in minimum essential medium (MEM; Gibco; Thermo Fisher Scientific, Inc., Waltham, MA, USA) supplemented with $20 \%$ fetal bovine serum (FBS; Gibco; Thermo Fisher Scientific, Inc.) in a humidified atmosphere containing $5 \% \mathrm{CO}_{2}$ at $37^{\circ} \mathrm{C}$.

Induction of apoptosis in HLE-B3 cells. $\mathrm{H}_{2} \mathrm{O}_{2}$-induced HLE-B3 cells used in subsequent experiments were gradually deprived of serum via an overnight culture in MEM containing $2 \% \mathrm{FBS}$, prior to being treated with $50 \mu \mathrm{M} \mathrm{H}_{2} \mathrm{O}_{2}$ for various time periods $(4,8$ and $12 \mathrm{~h})$ at $37^{\circ} \mathrm{C}$.

Vector construction and cell transfection. To induce Eaf2 overexpression, the full-length cDNA (NC_000003.12) for the human Eaf2 gene was obtained from the total RNA of human HLE-B3 cells isolated using TRIzol reagent (Invitrogen; Thermo Fisher Scientific, Inc.) using reverse transcription-quantitative polymerase chain reaction (RT-qPCR) and cloned into a pcDNA3.0 vector (Invitrogen; Thermo Fisher Scientific, Inc.) to generate pcDNA-Eaf2, which was subsequently designated as oeEaf2. The pcDNA3.0 empty plasmid was used as a negative control, which was designated as oeCon. Vector transfection was performed using Lipofectamine 2000 transfection reagent (Invitrogen; Thermo Fisher Scientific, Inc.) according to the manufacturer's protocol for $48 \mathrm{~h}$. Cells overexpressing Eaf2 also underwent Wnt $3 a$ knockdown. The Wnt $3 a$ short hairpin (sh)RNA plasmid (5'-AGAAGUAUCCGA GUGGGGCCA-3') used to knockdown Wnt3a was purchased from Santa Cruz Biotechnology, Inc. (Dallas, TX, USA) and was designated as shWnt3a. Subsequently, cells overexpressing Eaf2 were identified and transfected with shWnt3a and control shRNA (shCon; 5'-ACGUGACACGUUCGGAGAATT-3') using Lipofectamine ${ }^{\circledR} 2000$ transfection reagent (Invitrogen; Thermo Fisher Scientific, Inc.) according to the manufacturer's protocol for $48 \mathrm{~h}$. Cells were then cultured in 6-well plates at an inoculation density of $2 \times 10^{4}$ cells/well. The resulting constructs were confirmed using RT-qPCR and western blot analysis, and were used for subsequent experiments.

Lactate dehydrogenase $(\mathrm{LDH})$ release assay. To detect apoptosis, the release of LDH was assessed using an LDH assay kit (Nanjing Jiancheng Bioengineering Institute, Nanjing, China) according to the manufacturer's protocol. This method is used to measure the loss of membrane integrity by quantifying the release of $\mathrm{LDH}$ into the medium.
Flow cytometric analysis of apoptosis. Following exposure to the respective treatments, HLE-B3 cells were washed with PBS and subjected to a PI/Annexin V-FITC Apoptosis Detection kit (JingMei Biotech, Beijing, China): Briefly, $5 \mu 1$ Annexin $\mathrm{V}$-fluorescein isothiocyanate and $5 \mu \mathrm{l}$ propidium iodide (PI) were added to the suspended cells, which were gently vortexed and incubated for $15 \mathrm{~min}$ at room temperature in the dark. Following incubation, the cells were analyzed by flow cytometry (Accuri C6; BD Biosciences, Franklin Lakes, NJ, USA). Flow cytometric analysis was performed in triplicate.

RNA isolation and RT-qPCR analysis. Total RNA was extracted from cells using TRIzol reagent (Invitrogen; Thermo Fisher Scientific, Inc.) according to the manufacturer's protocol. cDNA was synthesized from the RNA using SuperScript II RT (200 U/ml; Invitrogen; Thermo Fisher Scientific, Inc.) according to the manufacturer's protocol. $\beta$-actin served as an endogenous control in the qPCR analysis. The following primers were used: $\beta$-catenin, forward 5'-GCC ACAAGATTACAAGAACGG-3', reverse 5'-TGGGCACCA ATATCAAGTCC-3'; caspase 3, forward 5'-TGGTTCATC CAGTCGCTTTG-3', reverse 5'-AATTCTGTTGCCACC TTTCG-3'; Eaf2, forward 5'-AGGTGACCATAACTCTGC CAAAT-3', reverse, 5'-AGCCGACATTCTCCAGTATCA-3'; Wnt3a, forward 5'-GTCCACGCCATTGCCTCAG-3', reverse, 5'-GACACCATCCCACCAAACTCG-3'; B-cell lymphoma 2 (Bcl-2)-associated $\mathrm{X}$ protein (Bax), forward 5'-GCAAAC TGGTGCTCAAGGC-3', reverse 5'-GCACTCCCGCCA CAAAGA-3'; and Bcl-2, forward 5'-TGTGGCCTTCTT TGAGTTCG-3' and reverse 5'-ATCCCAGCCTCCGTT ATCC-3'; $\beta$-actin, forward: 5'-CTTAGTTGCGTTACACCC TTTCTTG-3', reverse: 5'-CTGTCACCTTCACCGTTCCAG TTT-3'. The RT-qPCR analyses were performed in triplicate on a Bio-Rad Connect Real-Time PCR platform (Bio-Rad Laboratories, Inc., Hercules, CA, USA) using a $20 \mu \mathrm{l}$ reaction mixture containing $10 \mu 1$ XX SYBR Premix Ex Taq, $0.5 \mu$ leach

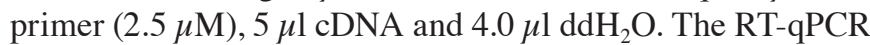
procedure was conducted as follows: Initial denaturation at $95^{\circ} \mathrm{C}$ for $1 \mathrm{~min}$, followed by 40 cycles of denaturation at $95^{\circ} \mathrm{C}$ for $5 \mathrm{sec}$ and annealing extension at $60^{\circ} \mathrm{C}$ for $20 \mathrm{sec}$, followed by $72^{\circ} \mathrm{C}$ for $20 \mathrm{sec}$. Human $\beta$-actin was used as an internal loading control for RT-qPCR. The $2^{-\Delta \Delta C q}(20)$ method was used to determine the relative mRNA expression levels of human $\beta$-catenin, caspase 3, Eaf2, Wnt3a, Bcl-2 and Bax. These levels were normalized to those of $\beta$-actin.

Western blot analysis. Treated HLE-B3 cells were harvested via centrifugation $(14,000 \mathrm{x} \mathrm{g} 4 \mathrm{~min})$ at $4^{\circ} \mathrm{C}$. Subsequently, the pelleted cells were lysed in a $2 \mathrm{X}$ SDS lysis buffer containing 100 mM Tris-HCl (pH 6.8), 10 mM EDTA, 4\% SDS and 10\% glycine. The lysed cells were then centrifuged at $15,000 \mathrm{x} \mathrm{g}$ for $15 \mathrm{~min}$ at $4^{\circ} \mathrm{C}$, the supernatant fractions were collected and protein concentrations were assessed using the bicinchoninic acid protein assay. Supernatant aliquots containing $\sim 30 \mu \mathrm{g}$ protein were separated by $12 \%$ SDS-PAGE. The proteins were then transferred onto polyvinylidene fluoride membranes by electrophoresis at $300 \mathrm{~mA}$ for $2 \mathrm{~h}$. The membranes were then blocked with $5 \%$ non-fat milk, and were washed with TBST and probed overnight at $4^{\circ} \mathrm{C}$ with $1: 1,000$ dilutions of primary antibodies, all from Cell Signaling Technology, 
A

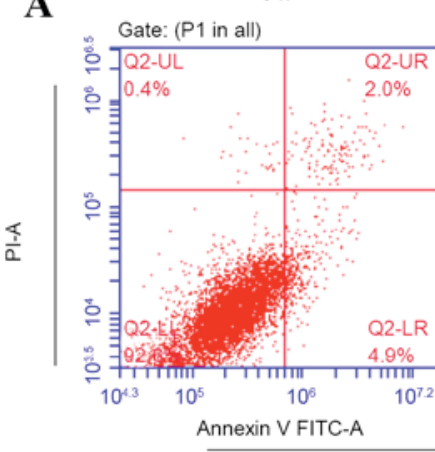

$4 \mathrm{~h}$

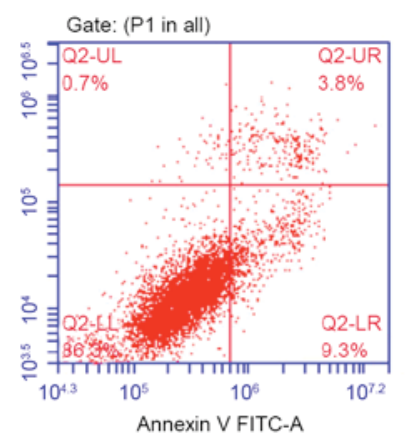

$8 \mathrm{~h}$

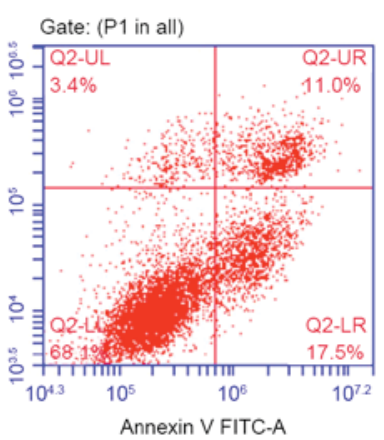

$12 \mathrm{~h}$

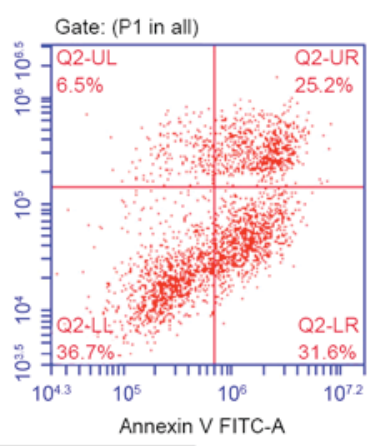

Annexin V FITC-A
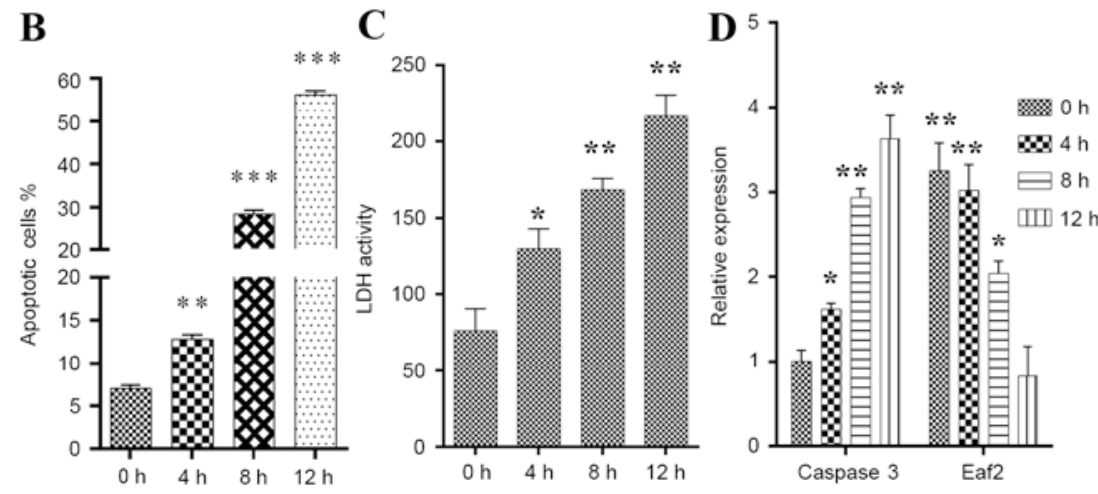

E

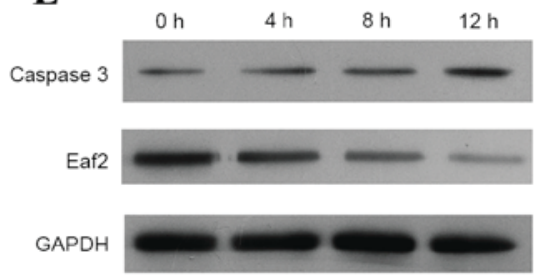

Figure 1. Construction of the $\mathrm{H}_{2} \mathrm{O}_{2}$-induced apoptotic HLE-B3 cell model. (A) Representative images showing the time-dependent uptake of Annexin V/PI by $\mathrm{H}_{2} \mathrm{O}_{2}$-induced HLE-B3 cells. (B) Quantification of overall apoptotic cells in a population of HLE-B3 cells, as determined by flow cytometry. Annexin $\mathrm{V}^{+} / \mathrm{PI}^{-}$, early apoptotic cells; Annexin $\mathrm{V}^{+} / \mathrm{PI}^{+}$, late apoptotic cells. (C) Quantification of LDH activity in a population of HLE-B3 cells. (D) mRNA expression levels of caspase 3 and Eaf2 in $\mathrm{H}_{2} \mathrm{O}_{2}$-induced HLE-B3 cells, as determined by reverse transcription-quantitative polymerase chain reaction analysis. (E) Protein expression levels of caspase 3 and Eaf2 in $\mathrm{H}_{2} \mathrm{O}_{2}$-induced HLE-B3 cells, as determined by western blot analysis. ${ }^{*} \mathrm{P}<0.05$, ${ }^{* *} \mathrm{P}<0.01$, ${ }^{* * *} \mathrm{P}<0.001$ vs. control. Eaf2, ELL-associated factor 2; FITC, fluorescein isothiocyanate; $\mathrm{H}_{2} \mathrm{O}_{2}$, hydrogen peroxide; HLE, human lens epithelial; LDH, lactate dehydrogenase; PI, propidium iodide.

Inc., Danvers, MA, USA: $\beta$-catenin (8480), GSK3e (12456), p-GSK3 $\beta$ (5558), Bcl-2 (15071), Bax (5023), caspase 3 (9662), Eaf2 (14159), Wnt3a (2721), GAPDH (5174). Subsequently, the blots were incubated with the corresponding horseradish peroxidase-conjugated secondary antibodies (Cell Signaling Technology, Inc.) for $45 \mathrm{~min}$ at $37^{\circ} \mathrm{C}$. Immunodetection was performed using the Super Enhanced Chemiluminescence Detection reagent according to the manufacturer's protocol (Thermo Fisher Scientific, Inc.).

Immunocytochemistry. Then, $24 \mathrm{~h}$ post-transfection, immunostaining was performed as previously described (3). Briefly, the treated HLE-B3 cells were fixed in 4\% paraformaldehyde in PBS for $15 \mathrm{~min}$ at room temperature, washed with PBS, and then permeabilized with $0.1 \%$ Triton X-100 in PBS for $5 \mathrm{~min}$. Subsequently, the cells were blocked for $1 \mathrm{~h}$ with PBS containing 5\% bovine serum albumin (Sigma-Aldrich; Merck $\mathrm{KGaA}$, Darmstadt, Germany) at room temperature and were incubated with primary antibodies (Eaf2; ab28357; Abcam and Wnt3a; ab28472; Abcam) for $1 \mathrm{~h}$ at room temperature. The cells were then incubated with the corresponding secondary antibodies (BM3894; Wuhan Boster Biological Technology, Ltd., Wuhan, China) for $1 \mathrm{~h}$ at room temperature. DAPI (Invitrogen; Thermo Fisher Scientific, Inc.) was used for counterstaining. Images of the immunostained cells were captured using a fluorescence microscope (VANOX-S; Olympus Corporation, Tokyo, Japan).
Statistical analysis. All statistical data were analyzed using GraphPad Prism 6.0 software (GraphPad Software, Inc., La Jolla, CA, USA), and results are expressed as the mean \pm standard deviation $(n=3)$. One-way analysis of variance was performed followed by post hoc least significant difference test for multiple comparisons. $\mathrm{P}<0.05$ was considered to indicate a statistically significant difference.

\section{Results}

Construction of an $\mathrm{H}_{2} \mathrm{O}_{2}$-induced apoptotic HLE cell model. HLE-B3 cells were induced to enter apoptosis by exposure to $\mathrm{H}_{2} \mathrm{O}_{2}$ for various time periods (4,8 and $12 \mathrm{~h}$ ). The apoptotic cells were detected by flow cytometry (Fig. 1A). Determination of the proportion of Annexin V-and PI-stained gated cells revealed that the population contained cells in both early stage (Annexin $\mathrm{V}^{+} / \mathrm{PI}^{-}$) and late stage (Annexin $\mathrm{V}^{+} / \mathrm{PI}^{+}$) apoptosis. The statistical analysis indicated that, when compared with the control cells, cell populations exposed to $50 \mu \mathrm{M} \mathrm{H}_{2} \mathrm{O}_{2}$ for $4(\mathrm{P}<0.01)$, $8(\mathrm{P}<0.001)$ and $12 \mathrm{~h}(\mathrm{P}<0.001)$ exhibited increased apoptosis (Fig. 1B). Similar patterns were also recorded in an $\mathrm{LDH}$ release assay (Fig. 1C). To further investigate the mechanism underlying $\mathrm{H}_{2} \mathrm{O}_{2}$-induced apoptosis, the expression levels of caspase 3 and Eaf 2 were detected in HLE-B3 cells. The results indicated that the mRNA (Fig. 1D; $\mathrm{P}<0.01$ ) and protein expression levels (Fig. 1E) of caspase 3 were markedly increased in HLE-B3 cells exposed to $\mathrm{H}_{2} \mathrm{O}_{2}$. Conversely, in HLE-B3 cells exposed to $\mathrm{H}_{2} \mathrm{O}_{2}$, 
A

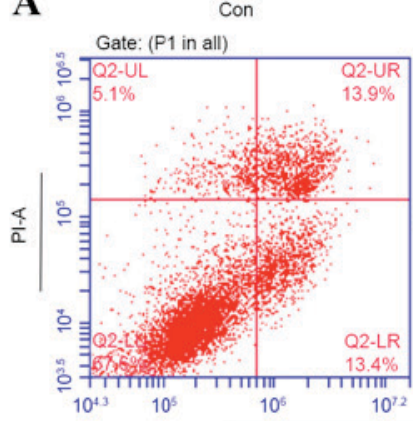

oeEaf2

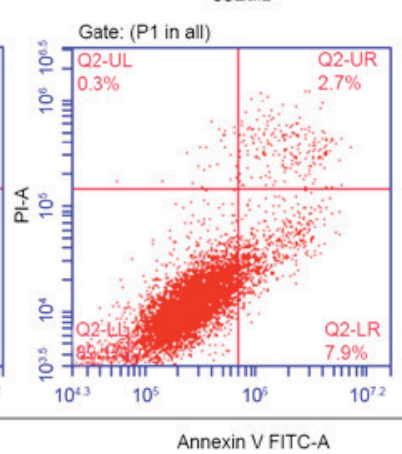

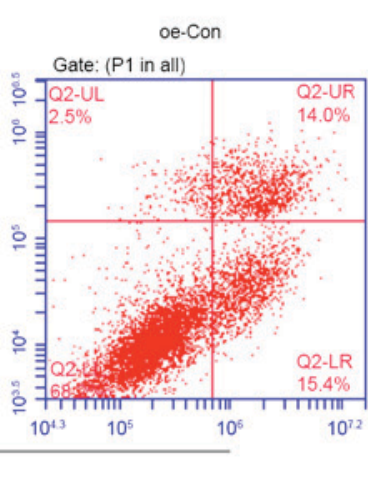

B

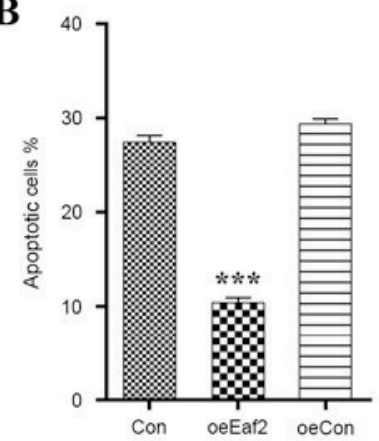

C

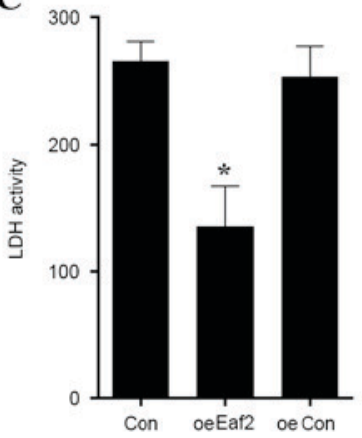

D

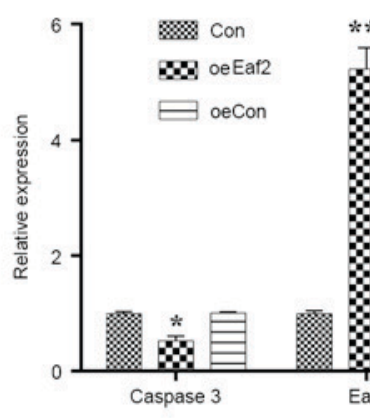

$\mathbf{F}$

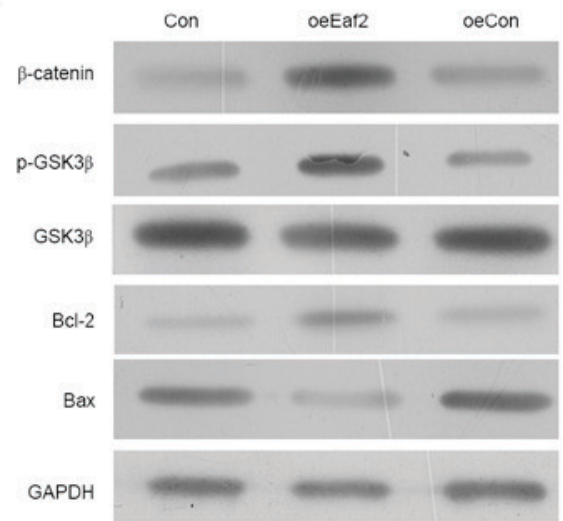

E

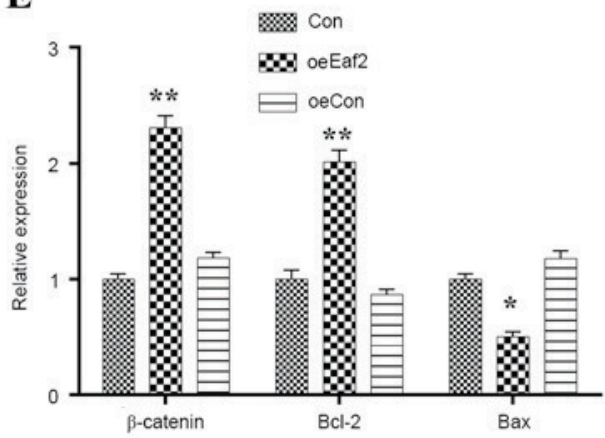

G

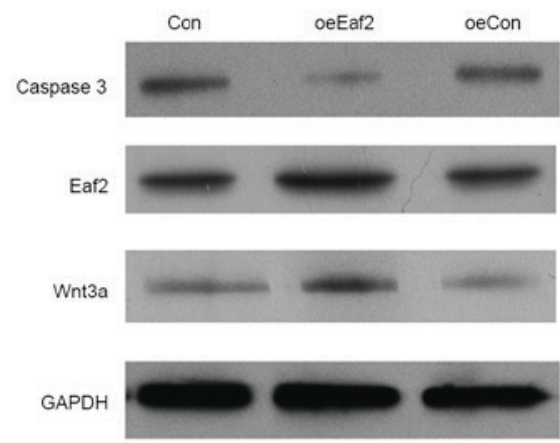

Figure 2. Effects of Eaf2 overexpression on $\mathrm{H}_{2} \mathrm{O}_{2}$-induced apoptosis of HLE-B3 cells. (A) Representative images of Annexin V/PI uptake by $\mathrm{H}_{2} \mathrm{O}_{2}$-induced HLE-B3 cells following Eaf2 overexpression, as determined by flow cytometry. (B) Quantification of apoptotic cells in $\mathrm{H}_{2} \mathrm{O}_{2}$-induced HLE-B3 cells overexpressing Eaf2. (C) Quantification of LDH activity in $\mathrm{H}_{2} \mathrm{O}_{2}$-induced HLE-B3 cells overexpressing Eaf2. Reverse transcription-quantitative polymerase chain reaction indicating the effects of Eaf2 overexpression on the mRNA expression levels of (D) caspase 3, Wnt3a and Eaf2, and (E) $\beta$-catenin, Bcl-2 and Bax in $\mathrm{H}_{2} \mathrm{O}_{2}$-treated HLE-B3 cells. Western blot analysis indicating the effects of Eaf2 overexpression on the protein expression levels of (F) $\beta$-catenin, p-GSK3 $\beta$, GSK3 $\beta$, Bcl-2 and Bax, and (G) Wnt3a, Eaf2 and caspase 3 in $\mathrm{H}_{2} \mathrm{O}_{2}$-treated HLE-B3 cells. ${ }^{*} \mathrm{P}<0.05,{ }^{* *} \mathrm{P}<0.01,{ }^{* * *} \mathrm{P}<0.001$ vs. Con or oeCon. Con represents the control group consisting of normal HLE-B3 cells; oeCon represents the negative control group consisting of HLE-B3 cells transfected with empty pcDNA3.0 plasmid; oeEaf2 represents the experimental group consisting of HLE-B3 cells transfected with pcDNA3.0-Eaf2. Bax, B-cell lymphoma 2-associated X protein; Bcl-2, B-cell lymphoma 2; GSK3 $\beta$, glycogen synthase kinase $3 \beta$; Eaf2, ELL-associated factor 2; FITC, fluorescein isothiocyanate; $\mathrm{H}_{2} \mathrm{O}_{2}$, hydrogen peroxide; HLE, human lens epithelial; LDH, lactate dehydrogenase; p, phosphorylated; PI, propidium iodide.

the mRNA (Fig. 1D; P<0.05) and protein expression levels (Fig. 1E) of Eaf2 were markedly downregulated, as determined by RT-qPCR and western blot analysis. Therefore, it may be hypothesized that Eaf2 protects HLE cells from entering apoptosis. $\mathrm{H}_{2} \mathrm{O}_{2}$ treatment for $12 \mathrm{~h}$ increased the number of early and late stage apoptotic cells by 6 - and 12 -fold, respectively, making those cells lose the potential to recover viability during subsequent analysis. Consequently, HLE-B3 cells that underwent $\mathrm{H}_{2} \mathrm{O}_{2}$ treatment for $8 \mathrm{~h}$ were used in subsequent experiments.

Overexpression of Eaf2 alleviates $\mathrm{H}_{2} \mathrm{O}_{2}$-induced apoptosis of HLE cells. To further investigate the effects of Eaf2 on
$\mathrm{H}_{2} \mathrm{O}_{2}$-induced HLE-B3 cells, cells were induced to overexpress Eaf 2 by transfection with a pcDNA-Eaf2 plasmid, after which various experiments were conducted (Figs. 2 and 3 ). Apoptosis was analyzed by Annexin V/PI double staining (Fig. 2A); the results indicated that a significantly lower percentage of cells overexpressing Eaf 2 had entered apoptosis (Fig. 2B). Overexpression of Eaf2 also decreased LDH activity (Fig. 2C), suggesting that the apoptotic process was suppressed. To investigate whether Eaf2 improves HLE-B3 cell survival rates by inhibiting apoptosis, the cellular levels of caspase 3 (a protease marker for apoptotic cell death) were analyzed by RT-qPCR and western blotting. The results demonstrated that, 
A
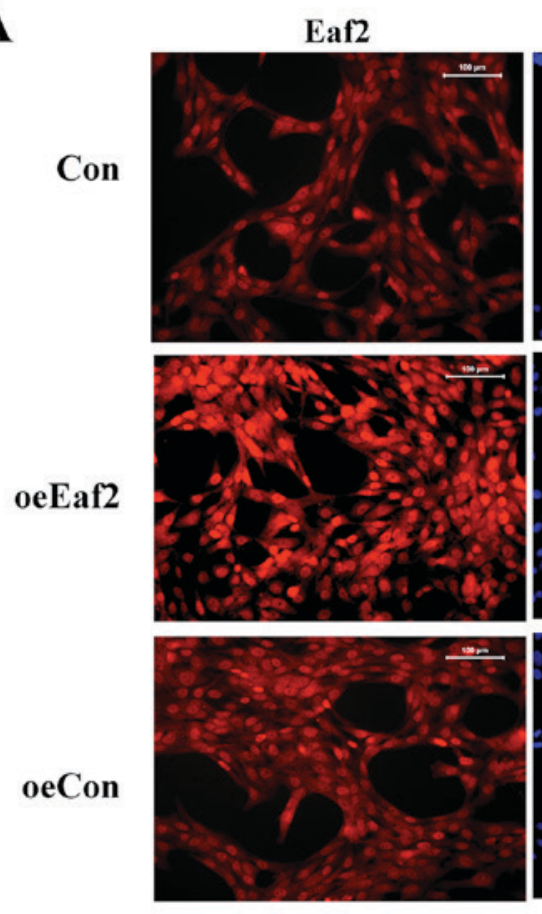

$\mathbf{B}$

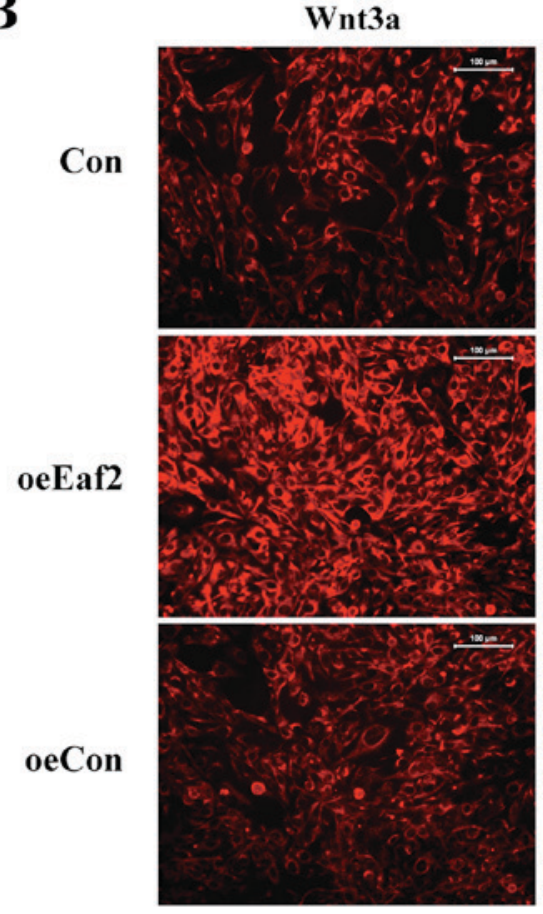

DAPI
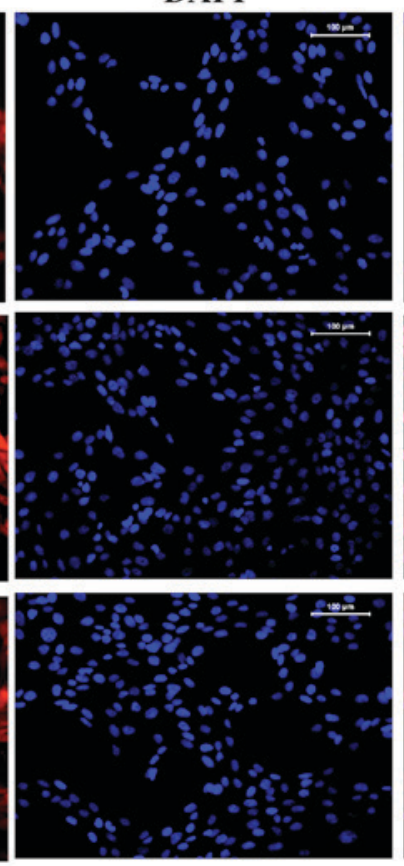

DAPI

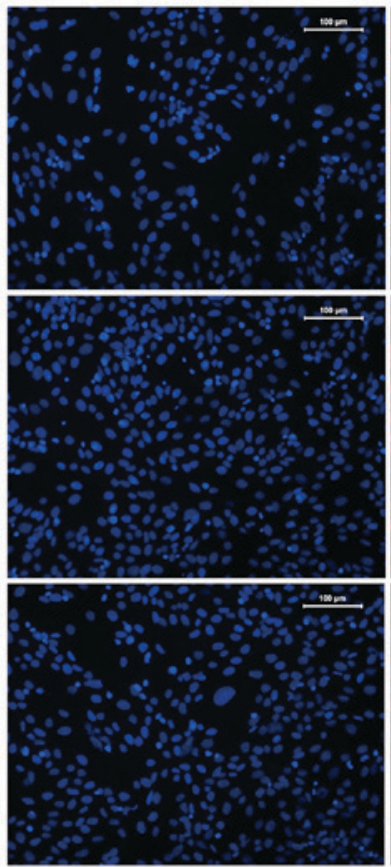

Merged
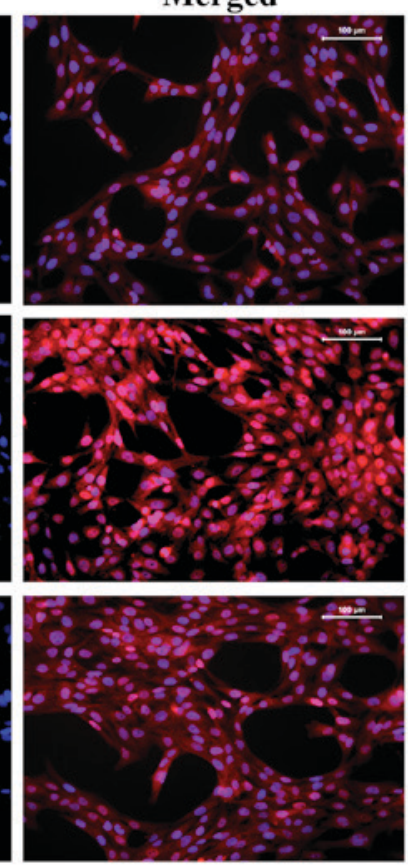

Merged

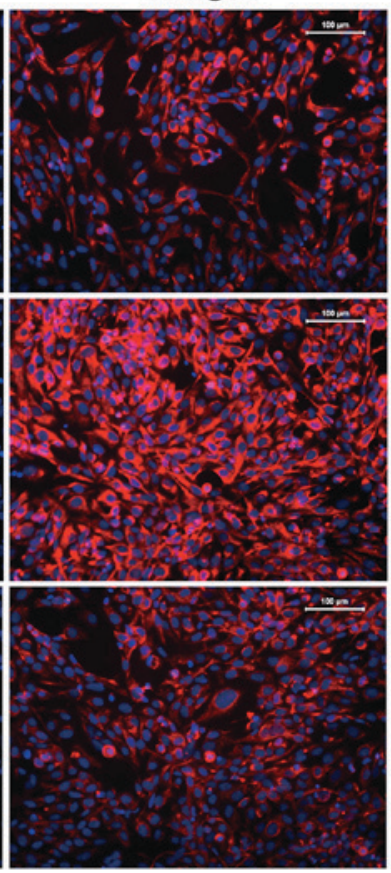

Figure 3. HLE-B3 cells as observed by fluorescence microscopy. Immunocytochemistry techniques were used to examine the expression levels of (A) Eaf2 and (B) Wnt3a in hydrogen peroxide-treated HLE-B3 cells overexpressing Eaf2. Con represents the control group consisting of normal HLE-B3 cells; oeCon represents the negative control group consisting of HLE-B3 cells transfected with empty pcDNA3.0 plasmid; oeEaf2 represents the experimental group consisting of HLE-B3 cells transfected with pcDNA3.0-Eaf2. Eaf2, ELL-associated factor 2; HLE, human lens epithelial.

when compared with the control cells, the mRNA (Fig. 2D; $\mathrm{P}<0.01$ ) and protein expression levels (Fig. 2G) of caspase 3 were markedly decreased in cells overexpressing Eaf2. Since it has been reported that a hyperactive Wnt pathway serves a role in early eye development (21), the present study examined the expression levels of $\beta$-catenin, phosphorylated (p)-GSK3 $\beta$ and Wnt3a expression in HLE-B3 cells overexpressing Eaf2. As presented in Fig. 2D-G, cells overexpressing Eaf2 exhibited elevated expression levels of $\beta$-catenin, p-GSK3 $\beta$, Wnt3a and
Bcl-2 while decreased the expression of Bax, thus suggesting a close association between Eaf 2 and Wnt3a signaling. An immunofluorescence assay further confirmed the upregulation of Wnt3a in Eaf2-overexpressing cells compared with the control cells (Fig. 3).

Eaf2 inhibits $\mathrm{H}_{2} \mathrm{O}_{2}$-induced apoptosis in HLE cells by regulating Wnt $3 a$. To further investigate whether Eaf2 inhibits apoptosis of HLE-B3 cells by affecting Wnt3a signaling, Wnt3a expression 
A

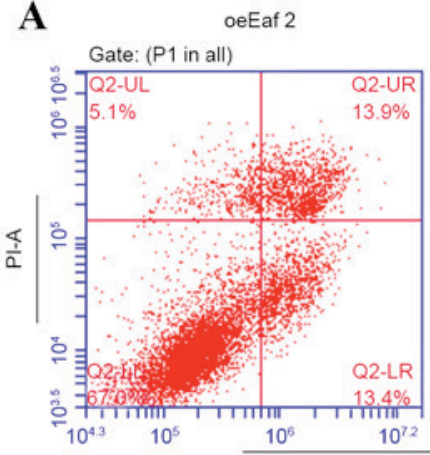

oeEAf 2+shWnt3a

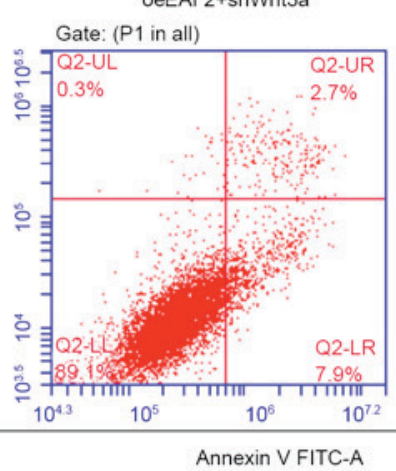

oeEAf $3+$ shCon

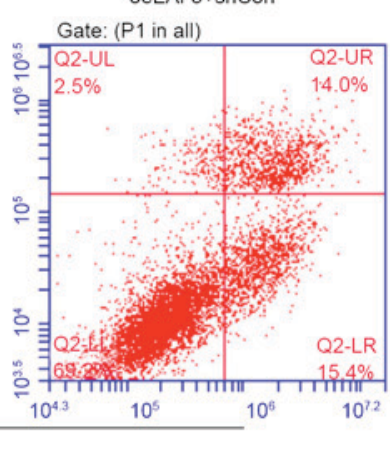

B

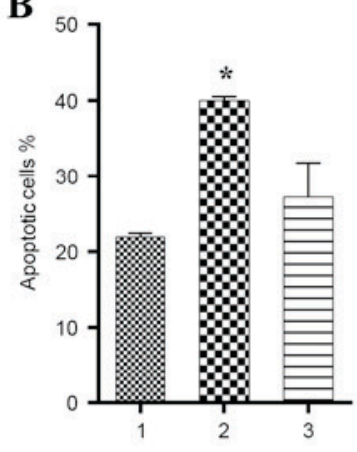

C

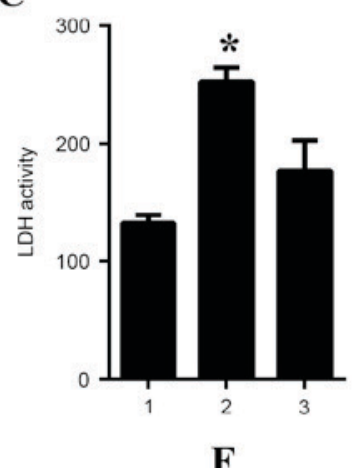

$\mathbf{F}$
D

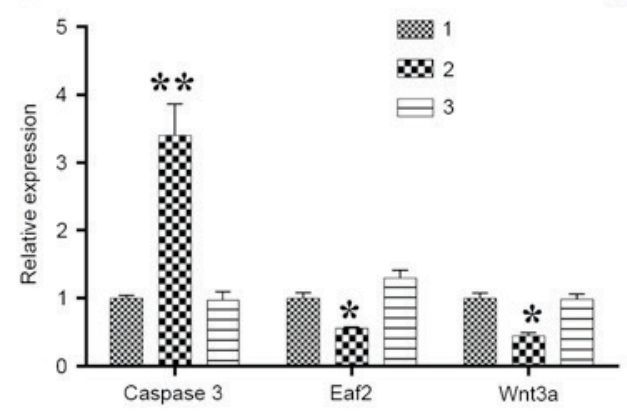

3

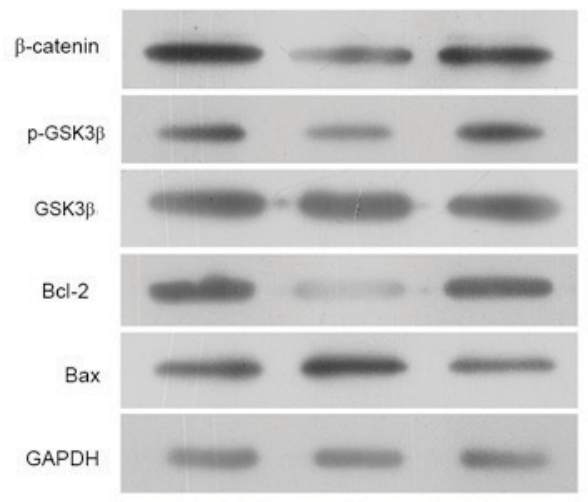

E

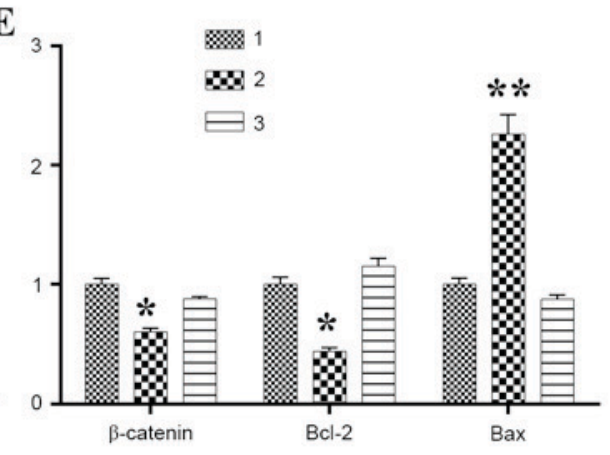

G

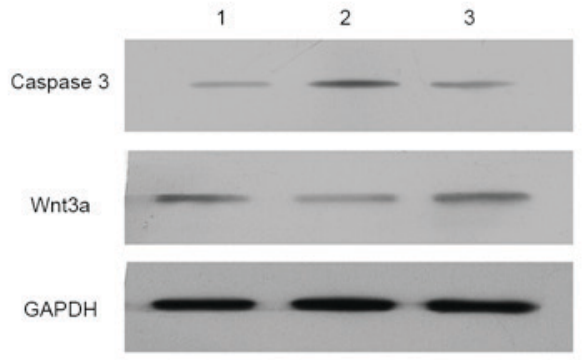

Figure 4. Effects of Wnt3a silencing on Eaf2 expression in HLE-B3 cells. (A) Representative images of Annexin V/PI uptake in Eaf2-overexpressing HLE-B3 cells following Wnt3a knockdown. (B) Quantification of apoptotic cells in Eaf2-overexpressing HLE-B3 cells following Wnt3a knockdown. (C) Quantification of LDH activity in Eaf2-overexpressing HLE-B3 cells following Wnt3a knockdown. Reverse transcription-quantitative polymerase chain reaction was conducted to determine the effects of Wnt3a silencing on the mRNA expression levels of (D) caspase 3, Eaf2 and Wnt3a, and (E) $\beta$-catenin, Bcl-2 and Bax in HLE-B3 cells overexpressing Eaf2. Western blot analysis was conducted to determine the effects of Wnt3a silencing on the protein expression levels of (F) $\beta$-catenin, p-GSK3 $\beta$, GSK3 $\beta$, Bcl-2 and Bax, and (G) caspase 3 and Wnt3a in HLE-B3 cells overexpressing Eaf2. ${ }^{*} \mathrm{P}<0.05,{ }^{* *} \mathrm{P}<0.01$ vs. control. Group 1 represents the oeEaf2 group consisting of HLE-B3 cells overexpressing Eaf2; group 2 represents the oeEaf2 + shWnt3a group consisting of Eaf2-overexpressing cells transfected with Wnt3a shRNA; group 3 represents the oeEaf2 + shCon group consisting of Eaf2-overexpressing cells transfected with control shRNA. Bax, B-cell lymphoma 2-associated X protein; Bcl-2, B-cell lymphoma 2; GSK3 $\beta$, glycogen synthase kinase 3ß; Eaf2, ELL-associated factor 2; FITC, fluorescein isothiocyanate; HLE, human lens epithelial; LDH, lactate dehydrogenase; p, phosphorylated; PI, propidium iodide; shRNA, short hairpin RNA.

was specifically knocked down in cells overexpressing Eaf2, and the cells were then examined by Annexin V/PI double staining (Fig. 4A). A statistical analysis indicated that the knockdown of Wnt3a significantly increased the overall percentage of Eaf2-overexpressing HLE-B3 cells undergoing apoptosis (Fig. 4B; $\mathrm{P}<0.05$ ). In addition, knockdown of Wnt $3 a$ reversed the Eaf 2 overexpression-induced suppression of $\mathrm{LDH}$ release, thus suggesting a key role for Wnt3a signaling in the function of Eaf2: That the role of Eaf2 in HLE-B3 cells depended on the activation of Wnt3a (Fig. 4C). Furthermore, the results suggested that Wnt3a knockdown promoted cell apoptosis by increasing the expression levels of caspase 3 and Bax while decreasing the expressions of $\beta$-catenin, p-GSK3 $\beta$, Bcl- 2 and Wnt3a (Fig. 4D and $G$ ). As presented in Fig. 5, an immunofluorescence analysis of Wnt3a expression was conducted in the various cell groups and the results showed that suppressed expression and distribution of Wnt3a was achieved in HLE-B3 cells.

\section{Discussion}

Oxidative stress is a major cause of cancer and cell death, and is thought to serve a major role in cataract formation (22). 


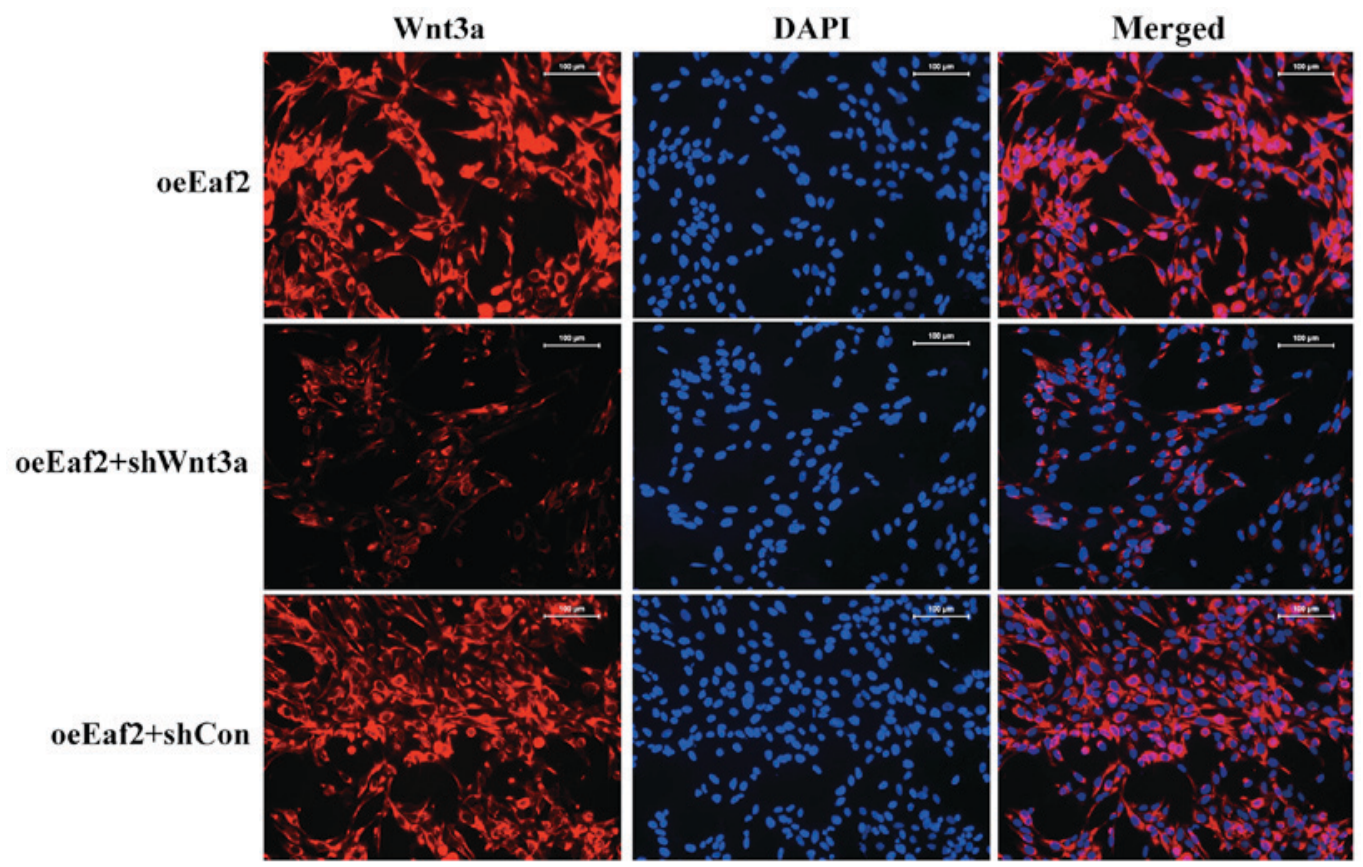

Figure 5. $\mathrm{H}_{2} \mathrm{O}_{2}$-treated HLE-B3 cells overexpressing Eaf2, as observed by fluorescence microscopy. Immunocytochemistry was used to examine Wnt3a expression in $\mathrm{H}_{2} \mathrm{O}_{2}$-treated Eaf2-overexpressing HLE-B3 cells following Wnt3a knockdown. The oeEaf2 group consists of HLE-B3 cells overexpressing Eaf2; the oeEaf2 + shWnt3a group consists of Eaf2-overexpressing cells transfected with Wnt3a shRNA; the oeEaf2 + shCon group consists of Eaf2-overexpressing cells transfected with control shRNA. Eaf2, ELL-associated factor 2; $\mathrm{H}_{2} \mathrm{O}_{2}$, hydrogen peroxide; HLE, human lens epithelial; shRNA, short hairpin RNA.

Previous studies have demonstrated that $\mathrm{H}_{2} \mathrm{O}_{2}$-induced oxidative stress can stimulate apoptosis of HLE cells, which form a single layer in the ocular lens $(3,5,23)$. Furthermore, this type of cellular stress may be considered the initiating factor for non-congenital cataract formation (24). In the present study, the role of the tumor suppressor Eaf 2 was determined in $\mathrm{H}_{2} \mathrm{O}_{2}$-induced apoptosis of lens cells. The results of the in vitro study suggested that Eaf 2 protects HLE cells from $\mathrm{H}_{2} \mathrm{O}_{2}$-induced apoptosis by regulating the expression levels of apoptosis-associated proteins. This conclusion was based on an analysis of data obtained from loss and gain-of-function experiments. Cellular apoptosis is an important physiological and pathological process, which results in the destruction of cell membranes and condensation of chromosomes (25). Furthermore, the activation of caspase proteases is regarded as the central mechanism of apoptosis. The levels of caspase 3 can be used to accurately reflect the levels of apoptosis in a cell population, particularly the levels of early stage apoptosis (26). Meanwhile, Bax and Bcl-2 expression serve as key roles in cell apoptosis. The present study observed that HLE cells began undergoing apoptosis in a time-dependent manner following exposure to $\mathrm{H}_{2} \mathrm{O}_{2}$. Furthermore, their entry into apoptosis was accompanied by the activation of caspase 3 and Bax, and suppression of Bcl-2. In HLE cells, oxidative stress leads to apoptosis, which is a common cellular mechanism underlying cataract formation (27).

It has previously been reported that Eaf2 is spatially regulated in the lenses of embryonic mice (12). Another study demonstrated that Eaf2 is highly enriched in the developing eye, and is essential for normal eye development (13). In the present study, gradually decreasing levels of Eaf2 expression were detected over time in HLE cells undergoing $\mathrm{H}_{2} \mathrm{O}_{2}$-induced apoptosis. A further analysis indicated that in HLE cells overexpressing Eaf2, the rate of $\mathrm{H}_{2} \mathrm{O}_{2}$-induced apoptosis was decreased, thus suggesting that it protects HLE cells against oxidative stress-induced apoptosis.

Overexpression of Eaf2 resulted in a marked increase in the expression levels of Wnt3a in $\mathrm{H}_{2} \mathrm{O}_{2}$-induced cells. Conversely, knockdown of Wnt $3 a$ decreased Eaf2 expression, and thereby promoted apoptosis of HLE cells. Wnt3a signaling is reportedly involved in the regulation of ocular cell proliferation and eye development $(21,28)$. A previous study demonstrated that Wnt $3 a$ overexpression promotes the proliferation of HLE-B3 cells by increasing the percentage of cells in $\mathrm{S}$ phase (18). Furthermore, the loss of Eaf2 function has been reported to result in a loss of eye function, and the loss of Wnt-4 function can be reversed by Eaf2 (13). Based on these findings, it may be concluded that Eaf2 suppresses $\mathrm{H}_{2} \mathrm{O}_{2}$-induced apoptosis via its effects on Wnt3a signaling. In addition, immunocytochemistry studies also revealed that Eaf 2 can influence the expression of Wnt3a, and affect Wnt3a expression levels. This finding may further explain how Eaf2 regulates the percentage of lens cells undergoing $\mathrm{H}_{2} \mathrm{O}_{2}$-induced apoptosis.

In conclusion, to the best of our knowledge, these data are the first to demonstrate that Eaf2 gene transcription products can protect HLE cells from oxidative damage caused by exposure to $\mathrm{H}_{2} \mathrm{O}_{2}$. In addition, the results of the present study demonstrated that when overexpressed, Eaf 2 can reduce $\mathrm{H}_{2} \mathrm{O}_{2}$-induced cell death by decreasing the expression levels of caspase 3 and Bax, and increasing Wnt3a and Bcl-2 expression. These results provide a theoretical foundation for the development of novel drugs for the treatment of cataracts. The present study focused on cell apoptosis and the suppressive effects of Eaf 2 on apoptosis; however, further studies are required to explain how Eaf2 affects apoptosis. 


\section{References}

1. Wormstone IM, Collison DJ, Hansom SP and Duncan G: A focus on the human lens in vitro. Environ Toxicol Pharmacol 21: 215-221, 2006

2. Pascolini D and Mariotti SP: Global estimates of visual impairment: 2010. Br J Ophthalmol 96: 614-618, 2011.

3. Wang Z, Wang D, Li Y and Zhang X: Protective effects of verapamil against $\mathrm{H} 2 \mathrm{O} 2$-induced apoptosis in human lens epithelial cells. Biomol Ther (Seoul) 22: 553-557, 2014.

4. Ottonello S, Foroni C, Carta A, Petrucco S and Maraini G: Oxidative stress and age-related cataract. Ophthalmologica 214: 78-85, 2000

5. Seomun Y, Kim JT, Kim HS, Park JY and Joo CK: Induction of p21Cip1-mediated $\mathrm{G} 2 / \mathrm{M}$ arrest in $\mathrm{H} 2 \mathrm{O} 2$-treated lens epithelial cells. Mol Vis 11: 764-774, 2005.

6. Spector A: Oxidative stress-induced cataract: Mechanism of action. FASEB J 9: 1173-1182, 1995.

7. Spector A and Garner WH: Hydrogen peroxide and human cataract. Exp Eye Res 33: 673-681, 1981.

8. Simone F, Luo RT, Polak PE, Kaberlein JJ and Thirman MJ: ELL-associated factor 2 (EAF2), a functional homolog of EAF1 with alternative ELL binding properties. Blood 101: 2355-2362, 2003.

9. Kong SE, Banks CA, Shilatifard A, Conaway JW and Conaway RC: ELL-associated factors 1 and 2 are positive regulators of RNA polymerase II elongation factor ELL. Proc Natl Acad Sci USA 102: 10094-10098, 2005.

10. Xiao W, Zhang Q, Jiang F, Pins M, Kozlowski JM and Wang Z: Suppression of prostate tumor growth by U19, a novel testosterone-regulated apoptosis inducer. Cancer Res 63: 4698-4704, 2003

11. Xiao W, Zhang Q, Habermacher G, Yang X, Zhang AY, Cai X, Hahn J, Liu J, Pins M, Doglio L, et al: U19/Eaf2 knockout causes lung adenocarcinoma, B-cell lymphoma, hepatocellular carcinoma and prostatic intraepithelial neoplasia. Oncogene 27: $1536-1544,2008$.

12. Li M, Wu X, Zhuang F, Jiang S, Jiang M and Liu YH: Expression of murine ELL-associated factor 2 (Eaf2) is developmentally regulated. Dev Dyn 228: 273-280, 2003.

13. Maurus D, Héligon C, Bürger-Schwärzler A, Brändli AW and Kühl M: Noncanonical Wnt-4 signaling and EAF2 are required for eye development in Xenopus laevis. EMBO J 24: 1181-1191, 2005.

14. Heisenberg CP, Tada M, Rauch GJ, Saúde L, Concha ML, Geisler R, Stemple DL, Smith JC and Wilson SW: Silberblick/Wnt11 mediates convergent extension movements during zebrafish gastrulation. Nature 405: 76-81, 2000.

15. Kilian B, Mansukoski H, Barbosa FC, Ulrich F, Tada M and Heisenberg CP: The role of Ppt/Wnt5 in regulating cell shape and movement during zebrafish gastrulation. Mech Dev 120: 467-476, 2003
16. Liu JX, Hu B, Wang Y, Gui JF and Xiao W: Zebrafish eaf1 and eaf2/u19 mediate effective convergence and extension movements through the maintenance of wnt11 and wnt5 expression. J Biol Chem 284: 16679-16692, 2009.

17. Clevers H: Wnt/beta-catenin signaling in development and disease. Cell 127: 469-480, 2006

18. Bao XL, Song H, Chen Z and Tang X: Wnt3a promotes epithelial-mesenchymal transition, migration, and proliferation of lens epithelial cells. Mol Vis 18: 1983-1990, 2012.

19. Jiang Y, Fu R, Zhao J, Wu D, Qiao G, Li R and Zhang J: Effects of ELL-associated factor 2 on ultraviolet radiation-induced cataract formation in mice. Mol Med Rep 12: 6605-6611, 2015.

20. Livak KJ and Schmittgen TD: Analysis of relative gene expression data using real-time quantitative PCR and the 2(-Delta Delta C(T)) method. Methods 25: 402-408, 2001.

21. Rasmussen JT, Deardorff MA, Tan C, Rao MS, Klein PS and Vetter ML: Regulation of eye development by frizzled signaling in Xenopus. Proc Natl Acad Sci USA 98: 3861-3866, 2001.

22. Dai J, Liu H, Zhou J and Huang K: Selenoprotein R protects human lens epithelial cells against d-Galactose-induced apoptosis by regulating oxidative stress and endoplasmic reticulum stress. Int J Mol Sci 17: 231, 2016.

23. Mao YW, Xiang H, Wang J, Korsmeyer S, Reddan J and Li DW: Human bcl-2 gene attenuates the ability of rabbit lens epithelial cells against $\mathrm{H} 2 \mathrm{O} 2$-induced apoptosis through down-regulation of the alpha B-crystallin gene. J Biol Chem 276: 43435-43445, 2001.

24. Takamura Y, Sugimoto Y, Kubo E, Takahashi Y and Akagi Y: Immunohistochemical study of apoptosis of lens epithelial cells in human and diabetic rat cataracts. Jpn J Ophthalmol 45: 559-563, 2001.

25. Blankenberg FG and Strauss HW: Recent advances in the molecular imaging of programmed cell death: Part I-pathophysiology and radiotracers. J Nucl Med 53: 1659-1662, 2012.

26. Li J and Yuan J: Caspases in apoptosis and beyond. Oncogene 27: 6194-6206, 2008.

27. Li WC, Kuszak JR, Dunn K, Wang RR, Ma W, Wang GM, Spector A, Leib M, Cotliar AM, Weiss M, et al: Lens epithelial cell apoptosis appears to be a common cellular basis for non-congenital cataract development in humans and animals. J Cell Biol 130: 169-181, 1995.

28. Shang YC, Wang SH, Xiong F, Zhao CP, Peng FN, Feng SW, Li MS, Li Y and Zhang C: Wnt3a signaling promotes proliferation, myogenic differentiation, and migration of rat bone marrow mesenchymal stem cells. Acta Pharmacol Sin 28: 1761-1774, 2007.

This work is licensed under a Creative Commons Attribution-NonCommercial-NoDerivatives 4.0 International (CC BY-NC-ND 4.0) License. 